\title{
Critical appraisal of ramelteon in the treatment of insomnia
}

\author{
This article was published in the following Dove Press journal: \\ Nature and Science of Sleep \\ 9 November 2010 \\ Number of times this article has been viewed
}

\section{Monique AJ Mets \\ Kenny R van Deventer \\ Berend Olivier \\ Joris C Verster}

Utrecht University, Utrecht Institute for Pharmaceutical Sciences, Division of Pharmacology, Utrecht,

The Netherlands
Correspondence: MAJ Mets PO Box 80082, 3508 TB Utrecht, The Netherlands

Tel +3I 302537764

Fax +3I 302537900

Email m.a.J.mets@uu.nl

\begin{abstract}
Ramelteon is the first member of a novel class of hypnotics and acts as a selective melatonin receptor agonist. In 2005, ramelteon was approved by the US Food and Drug Administration for the treatment of insomnia characterized by sleep onset problems. Its unique mechanism of action made it a promising candidate compared with the widely used hypnotics that act on the benzodiazepine receptor complex. Several studies have examined its efficacy and safety as a hypnotic agent. The primary efficacy of ramelteon was found to lie in a decrease in latency to persistent sleep, as measured by polysomnographic tests. Other sleep-related measures, such as total sleep time and number of nightly awakenings, show less pronounced improvement when treated with ramelteon. In addition, no rebound insomnia or abuse potential was observed in clinical studies. Although additional studies are necessary, current data on the acute and next-morning effects of ramelteon did not indicate cognitive or psychomotor impairment. Overall, ramelteon is safe and well tolerated, although some questions remain regarding its long-term efficacy and safety. These issues and possibilities for use in other patient groups should be addressed in future research.
\end{abstract}

Keywords: ramelteon, melatonin, insomnia, hypnotics

\section{Introduction}

Until recently, pharmacologic treatment of insomnia largely relied on the prescription of hypnotic drugs belonging to the class of benzodiazepine receptor agonists. These include benzodiazepines, such as lormetazepam, temazepam, and triazolam, and z-drugs, including zaleplon, zolpidem, and zopiclone. Unfortunately, benzodiazepines have a number of adverse effects, including daytime sedation, memory and psychomotor impairment, dependence, and abuse potential. ${ }^{1}$ The more recently introduced $z$-drugs are equally effective, but have an improved safety profile. Because z-drugs also act at benzodiazepine receptors, similar adverse effects can be observed as seen with benzodiazepine hypnotics. ${ }^{2,3}$

Ramelteon is one of the new hypnotic drugs that does not act on the gammaaminobutyric acid (GABA) receptor, and is therefore believed to be an improvement relative to the traditional hypnotic drugs. Ramelteon is a selective melatonin receptor agonist, a hormone that is of importance in regulating the sleep-wake cycle.

Although ramelteon was approved by the US Food and Drug Administration (FDA) ${ }^{4}$ for use in insomnia characterized by sleep onset difficulties in 2005, the European Medicines Agency refused marketing authorization in 2008. The refusal was primarily based on a lack of consistent subjective efficacy. ${ }^{5}$ Since that time, a number of clinical studies have been published. This review updates previously published reviews, ${ }^{6-8}$ and aims to give an overview of the current knowledge on ramelteon. 


\section{Pharmacology}

The endogenous agent melatonin, a hormone synthesized in the pineal gland, aids sleep by shortening the latency to sleep onset and by maintaining sleep. It is a key component in regulating circadian cycle. Besides its sleep-promoting effects, melatonin can also function as a chronobiotic, ie, it can regulate the internal clock. Melatonin exerts its sleep-promoting and chronobiotic actions by acting on the melatonin receptor-1 (MT1) and MT2 in the suprachiasmatic nucleus in the hypothalamus. The suprachiasmatic nucleus functions as an inner biologic clock regulating the sleep-wake cycle. The hypothalamus reacts to levels of light. In darkness, the hypothalamus will signal the pineal gland to produce melatonin. High levels of melatonin are associated with darkness, whilst low levels indicate light and wakefulness. When MT1 is occupied by a ligand, neuronal firing is restrained and, hence, sleep is induced. Phase shifting requires MT2 involvement. ${ }^{9,10}$ The third melatonin binding site is the enzyme quinone reductase 2 , which most likely mediates the antioxidant properties of melatonin. ${ }^{11}$

Furthermore, there is evidence that melatonin facilitates sleep by promoting spindle formation. Sleep spindles are characteristic of stage 2 sleep in the sleep electroencephalogram (EEG). They are generated in the reticular nuclei of the thalamus, and are of importance in the induction and maintenance of sleep. ${ }^{12}$ Changes in plasma melatonin levels were found to coincide with changes in EEG activity in the spindle range. ${ }^{13}$ In addition, an increase in power density in the sleep spindle frequency range was observed when exogenous melatonin was administered during the daytime. ${ }^{14}$

Ramelteon is a selective MT1 and MT2 agonist. Compared with melatonin, ramelteon has a six-fold higher binding potency for the human MT1 and a three-fold higher affinity for the human MT2. Ramelteon shows no affinity for quinone reductase 2. Ramelteon also has no affinity for GABA-ergic, cholinergic, or monoaminergic receptors. ${ }^{15}$ Its selectivity for MT1 and MT2 and lack of GABA affinity are found in both animals ${ }^{16-19}$ and humans. ${ }^{20}$ Because ramelteon is a selective melatonin receptor agonist, it exerts its pharmacologic actions in a similar manner to melatonin. ${ }^{9}$ The effect of ramelteon on sleep spindles has not been studied.

\section{Pharmacokinetics}

After oral administration, ramelteon is rapidly absorbed and reaches peak serum concentrations after one hour. Its bioavailability is less than $2 \%$, due to extensive first-pass metabolism. The active M-II metabolite is formed after hydroxylation mediated through the cytochrome P-450 (CYP450) isoenzyme 1A2. M-II has about one-tenth and one-fifth the binding affinity of ramelteon for the MT1 and MT2 receptors, respectively, and is 17- to 25-fold less potent in in vitro functional assays. However, systemic exposure to $\mathrm{M}-\mathrm{II}$ is 20 - to100-fold greater than the parent compound itself, with peak concentrations after approximately one hour. Its elimination half-life is two to four hours, compared with the one- to two-hour elimination half-life of ramelteon. With the exception of a weak affinity for the serotonin (5-HT) 2B receptor, M-II has no noteworthy affinity for other receptors or enzymes. ${ }^{20-22}$ Given its availability and affinity, M-II is likely to contribute to the effect of ramelteon, but the magnitude of this effect is unknown. The influence of age and gender on kinetics and dynamics was investigated in healthy volunteers. ${ }^{20}$ Age significantly influenced the pharmacokinetics of ramelteon. In older subjects (60-79 years), the maximum serum concentration, elimination half-life, and area under the curve (AUC), ie, biologic availability, of ramelteon were increased compared with younger subjects (18-35 years). In addition, the M-II metabolite had a longer elimination half-life and higher AUC, as well as a reduction in clearance of $43 \%$. Unlike age, gender does not influence the kinetics of ramelteon. ${ }^{20}$

\section{Efficacy}

Various studies described in the following sections have examined different dosages of ramelteon. It should be kept in mind that the recommended dose of ramelteon for the treatment of insomnia is $8 \mathrm{mg}$, taken at bedtime.

\section{Single administration in healthy subjects}

Two randomized, double-blind, placebo-controlled studies examined the efficacy of a single dose of ramelteon. Transient insomnia was induced in healthy adult volunteers by introducing a novel sleep environment, ie, a sleep laboratory. In the first study ${ }^{23}$ healthy adult volunteers (35-60 years) received a single dose of ramelteon $16 \mathrm{mg}(\mathrm{n}=126), 64 \mathrm{mg}$ $(\mathrm{n}=126)$, or placebo $(\mathrm{n}=123) 30$ minutes before bedtime. Polysomnographic recordings showed that, compared with placebo, the $16 \mathrm{mg}$ dose reduced latency to persistent sleep by 10.5 minutes and increased total sleep time by 14.1 minutes. Ramelteon $64 \mathrm{mg}$ reduced latency to persistent sleep by 9.1 minutes and increased total sleep time by 11.1 minutes. In the second study, ${ }^{24}$ adult subjects (18-64 years) received a single dose of ramelteon $8 \mathrm{mg}(\mathrm{n}=98)$, ramelteon $16 \mathrm{mg}(\mathrm{n}=94)$, or placebo $(\mathrm{n}=97) 1.5-2.0$ hours before bedtime. A significant decrease in latency to persistent 
sleep (7.5 minutes) was found after administration of $8 \mathrm{mg}$ ramelteon, but no statistically significant effect was found for the $16 \mathrm{mg}$ dose. Total sleep time increased by 17.1 minutes with the $8 \mathrm{mg}$ dose and by 13.4 minutes with the $16 \mathrm{mg}$ dose. Neither study showed an effect on sleep architecture, ie, pattern of sleep stages and number of nightly awakenings, or on subjective sleep measures.

\section{Chronic insomnia in adults}

An overview of double-blind clinical studies in chronic insomnia patients is provided in Table 1. All studies were randomized, double-blind, and placebo-controlled, with ramelteon administered at bedtime. Latency to persistent sleep, the primary endpoint in three studies performed in adults, ${ }^{25-27}$ was significantly reduced by ramelteon 4-32 mg. This decrease was sustained when patients were treated for up to six months (see Figure 1).
In patients treated for up to five weeks, the decrease in latency to persistent sleep varied from 11 to 19 minutes. Total sleep time increased for all dosages of ramelteon, but after one week of treatment, significant effects compared with placebo were no longer present. Overall, sleep architecture was slightly affected by ramelteon. Compared with placebo, decreases in percentage of time spent in slow wave sleep, ie, sleep stages 3 and 4, were found up to six months of treatment..$^{25-27}$ This was accompanied by an increase in stage 2 sleep in one study. ${ }^{25}$ An increase in percentage of time spent in rapid eye movement sleep was found after three weeks of treatment with ramelteon $16 \mathrm{mg} .{ }^{27}$ The relative decrease in sleep in stages 3 and 4 may be accounted for by an increase in total sleep time, and was therefore considered to be clinically irrelevant. ${ }^{27}$

Studies of ramelteon have revealed inconsistent effects on subjective sleep assessments. One study showed consistent

Table I Objective and subjective data on sleep-related measures in double-blind, placebo-controlled studies in chronic insomnia patients treated with ramelteon

\begin{tabular}{|c|c|c|c|c|c|c|c|c|c|c|c|c|c|}
\hline Subjects & $\begin{array}{l}\text { Dose } \\
(\mathrm{mg})\end{array}$ & $\begin{array}{l}\text { Treatment } \\
\text { duration }\end{array}$ & $\begin{array}{l}\text { Time } \\
\text { of test }\end{array}$ & $\begin{array}{l}\text { LPS } \\
(\mathrm{min})\end{array}$ & $\begin{array}{l}\text { TST } \\
(\mathrm{min})\end{array}$ & $\begin{array}{l}\text { WASO } \\
\text { (min) }\end{array}$ & $\begin{array}{l}\text { SE } \\
(\%)\end{array}$ & $\begin{array}{l}\text { sSL } \\
(\mathrm{min})\end{array}$ & $\begin{array}{l}\text { sTST } \\
(\mathrm{min})\end{array}$ & $\begin{array}{l}\text { sWASO } \\
\text { (min) }\end{array}$ & NAW & SQ & Reference \\
\hline Adults, $\mathrm{n}=335$ & 8 & 6 months & & & & & & & & & & & 25 \\
\hline I59 ramelteon, & & & $w l$ & - & +15.4 & & & - & NS & NS & NS & NS & \\
\hline I76 placebo; & & & $\mathrm{ml}$ & - & NS & & & - & NS & NS & NS & NS & \\
\hline mean age 46.2 & & & $\mathrm{~m} 3$ & - & NS & & & NS & NS & NS & NS & NS & \\
\hline \multirow[t]{2}{*}{ (18-79 years) } & & & $\mathrm{m} 5$ & - & NS & & & - & NS & NS & NS & NS & \\
\hline & & & $\mathrm{m} 6$ & - & NS & & & NS & NS & +11.4 & NS & NS & \\
\hline Adults, $n=405$ & & 35 nights & & & & & & & & & & & 26 \\
\hline divided over & 8 & & wl & -15.7 & +19 & NS & +4 & -17.3 & +24.2 & -13.8 & & NS & \\
\hline 3 treatments; & & & w3 & -12.9 & NS & NS & NS & -18.5 & +20.2 & NS & & NS & \\
\hline mean age & & & w5 & -11 & NS & NS & NS & -16.7 & +18.3 & NS & & NS & \\
\hline \multirow[t]{3}{*}{ approx 39 years } & 16 & & wl & -19 & +22.4 & NS & +5.1 & -13.9 & +22.4 & -18.3 & & NS & \\
\hline & & & w3 & -17.6 & NS & NS & NS & -11.4 & +9.6 & NS & & NS & \\
\hline & & & w5 & -13 & NS & NS & NS & NS & NS & NS & & NS & \\
\hline Adults, $\mathrm{n}=103$ & & 2 nights & & & & & & & & & & & 27 \\
\hline \multirow[t]{4}{*}{ age $18-64$ years } & 4 & & & -13.7 & +10.7 & NS & & NS & NS & & & NS & \\
\hline & 8 & & & -13.4 & +12.6 & NS & & NS & NS & & & NS & \\
\hline & 16 & & & -13.7 & +10.9 & NS & & -13.1 & NS & & & NS & \\
\hline & 32 & & & -14.8 & +17.9 & NS & & NS & NS & & & NS & \\
\hline Older adults, & & 35 nights & & & & & & & & & & & 30 \\
\hline$\geq 65$ years; & 4 & & wl & & & & & -8.3 & +10.7 & & NS & NS & \\
\hline $\mathrm{n}=829$ divided & & & w3 & & & & & NS & $+\mathrm{II}, 7$ & & NS & NS & \\
\hline \multirow[t]{5}{*}{ over 3 groups } & & & w5 & & & & & -7.2 & NS & & NS & NS & \\
\hline & 8 & & & & & & & & & & NS & NS & \\
\hline & & & wl & & & & & -8.3 & +7.2 & & NS & NS & \\
\hline & & & w3 & & & & & -9 & +7.8 & & NS & NS & \\
\hline & & & w5 & & & & & -12.9 & NS & & NS & NS & \\
\hline Older adults, $\mathrm{n}=100$ & & 2 nights & & & & & & & & & & & 31 \\
\hline (37 men, 63 women, & 4 & & & -9.7 & +9 & & +1.8 & -10 & NS & NS & +0.8 & NS & \\
\hline $65-83$ years) & 8 & & & -7.6 & +11.6 & & +2.4 & NS & NS & NS & NS & NS & \\
\hline
\end{tabular}

Abbreviations: LPS, latency to persistent sleep; TST, total sleep time; WASO, wake time after sleep onset; Eff, sleep efficiency (TST/total time in bed $\times$ I00); sSL, subjective sleep latency; sTST, subjective total sleep time; sWASO, subjective wake time after sleep onset; NAW, number of awakenings; SQ, sleep quality; w, week; NS, no significant change compared with placebo; $m$, month; +, significant increase; -, significant decrease. 

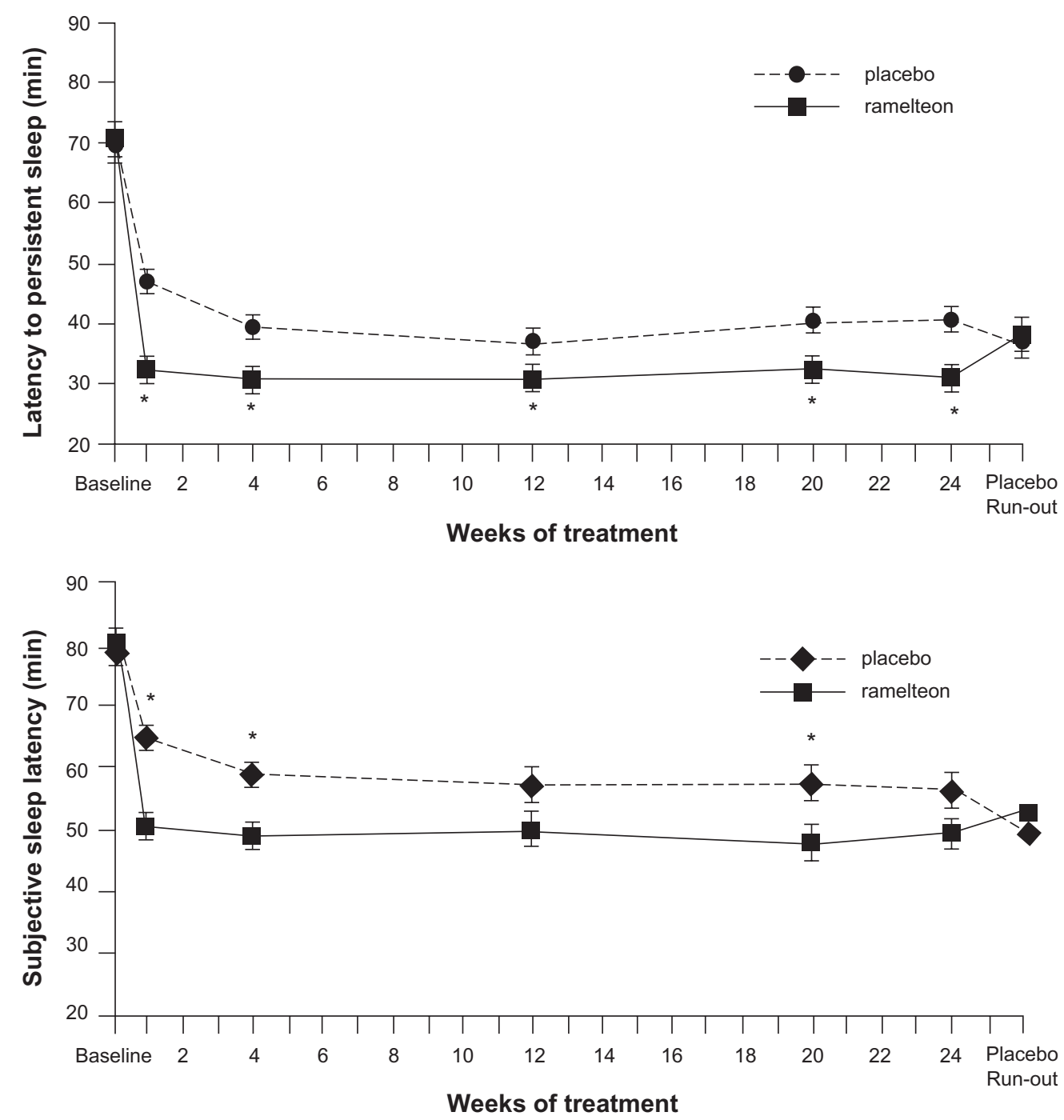

Figure I Polysomnography-measured latency to persistent sleep (top) and subjective sleep latency (bottom) over six months of double-blind ramelteon 8 mg or placebo treatment at night. Data are least-squares means with standard error bars.

Notes: *Significantly different from placebo $(P<0.05)$. Copyright $@ 2010$, American Academy of Sleep Medicine. Adapted with permission from Mayer G, Wang-Weigand S, Roth-Schechter B, Lehmann R, Staner C, Partinen M. Efficacy and safety of 6-month nightly ramelteon administration in adults with chronic primary insomnia. Sleep. 2009;32(3):35I-360. ${ }^{25}$

decreases in subjective sleep latency and increases in total sleep time,${ }^{26}$ but this was not the case in the other studies. ${ }^{25,27}$ Patients did not rate their sleeping quality as improved in any of the studies.

In an open-label study, 965 adult and 248 elderly insomniacs were administered ramelteon $8 \mathrm{mg}$ and $16 \mathrm{mg}$, respectively, for 48 weeks. ${ }^{28}$ During the study, self-reports in both groups revealed significant reductions in subjective sleep latency and increases in total sleep time. The self-reports were consistent with clinicians' reporting of reduced insomnia and therapeutic efficacy of ramelteon at months 6 and 12 .

Finally, a pooled analysis of four studies in subjects with chronic insomnia ${ }^{29}$ showed that when using ramelteon
$8 \mathrm{mg}$ for two nights, latency to persistent sleep decreased by 13 minutes when compared with placebo.

\section{Chronic insomnia in the elderly}

Two studies were performed in elderly insomnia patients. ${ }^{30,31} \mathrm{An}$ overview of the results is provided in Table 1. The first study examined subjective reports of sleep using sleep diaries. The study started with a single-blind placebo runin week, followed by five weeks of double-blind ramelteon $4 \mathrm{mg}$ or $8 \mathrm{mg}$ administration, and ended with a single-blind placebo runout period. ${ }^{30}$ Compared with placebo, sleep latency was decreased up to five weeks after treatment onset, except for the $4 \mathrm{mg}$ dose after three weeks. Subjective total sleep time 
was increased for up to three weeks of treatment. Results showed reductions in sleep latency ranging from 4.4 minutes ( $4 \mathrm{mg}$ after three weeks; $P=0.142$ ) to 12.9 minutes $(8 \mathrm{mg}$ after five weeks; $P<0.001)$.

Subgroup analysis revealed that patients with higher baseline sleep latency ( $>67.1$ minutes) had greater benefit from ramelteon. In these patients, reductions in subjective sleep latency compared with placebo ranged from 13.9 minutes (week 1, $4 \mathrm{mg}$ ) to 23.3 minutes (week 5, $8 \mathrm{mg}$ ). Additional analysis confirmed these findings. ${ }^{32}$ No rebound insomnia or withdrawal effects were found during the placebo runout week.

In a second randomized, double-blind study in elderly insomniacs, ${ }^{31}$ ramelteon $4 \mathrm{mg}$ and $8 \mathrm{mg}$ produced a significant decrease in latency to persistent sleep, a lower percentage of time spent in sleep stages 3 and 4, and a higher percentage of time spent in stage 1 sleep. Ramelteon $8 \mathrm{mg}$ also increased time spent in stage 2 sleep.

\section{Generalized anxiety disorder}

An open-label study was conducted in adults $(n=27$, mean age 41 years) with generalized anxiety disorder and comorbid insomnia. ${ }^{33}$ Generalized anxiety disorder patients were partially responsive to a selective serotonin reuptake inhibitor or serotonin norepinephrine reuptake inhibitor. For a period of 10 weeks, patients were also treated with ramelteon $8 \mathrm{mg}$. Sleep latency and total sleep time significantly improved when comparing data with baseline and poststudy visits ( -42.85 minutes and +2.5 hours, respectively). No effect on subjective wake time after sleep onset was observed. In addition, reductions were observed in insomnia symptoms, daytime sleepiness, and anxiety symptoms. These results should be confirmed by double-blind, placebo-controlled studies.

\section{Use of ramelteon as a chronobiotic}

Limited data are available on the efficacy of ramelteon as a chronobiotic, ie, its capability to act on the circadian clock. In rats, ramelteon enhanced adaptation to a new sleep-wake schedule. ${ }^{17}$ In humans, the chronobiotic effects of ramelteon were assessed in 75 healthy volunteers aged $18-45$ years. ${ }^{34}$ Five hours before their habitual bedtime, lights were switched off, thereby shifting the sleep-wake cycle by four hours. Subjects were randomized to treatment with ramelteon 1, 2, 4, or $8 \mathrm{mg}$ or placebo, administered 30 minutes prior to lights out for four consecutive days. The dim light melatonin secretion offset time, ie, the time at which melatonin production stops, was the primary measure for phase-advancing properties. In other words, the efficacy of ramelteon to induce phase shifts was measured by the extent to which endogenous melatonin levels adapted to the new sleep-wake schedule. After one day, the $4 \mathrm{mg}$ group achieved a significant shift compared with placebo, and a significant shift was evident after two days for the $1 \mathrm{mg}$ and $2 \mathrm{mg}$ groups. No significant effect was found for the highest dose. This is in agreement with a subsequent study in which jet lag was examined. ${ }^{35}$ Ramelteon dosages of 1,4 , or $8 \mathrm{mg}$ were administered to individuals who had flown eastward across five time zones, leading to a five-hour phase advance. Ramelteon was administered five minutes before the local bedtime. Ramelteon $1 \mathrm{mg}$ significantly decreased mean latency to persistent sleep after two to four nights of intake, but no effect was seen for the higher dosages. A possible explanation may be that remaining levels led to a phase shift in the opposite (undesired) direction. There was no effect on any of the other objective or subjective sleep measures. In contrast with the previous study, there were no differences in dim light melatonin offset. Therefore, it is possible that the observed effects may not be due to shifts of the circadian phase. Only the $4 \mathrm{mg}$ group showed improvements in subjective daytime functioning, alertness, and ability to concentrate.

\section{Safety and tolerability Withdrawal effects and rebound insomnia} Several double-blind studies ${ }^{25,26,30}$ with a single-blind placebo runout week were conducted to detect possible withdrawal effects or rebound insomnia. Rebound insomnia was defined as a mean latency to persistent sleep during placebo runout that was equal to or worse than sleep latency at baseline. A range of symptoms commonly experienced during benzodiazepine withdrawal were explored using the Tyrer Benzodiazepine Withdrawal Symptom Questionnaire. ${ }^{36}$ No withdrawal symptoms or rebound insomnia were detected after treatment with ramelteon $8 \mathrm{mg}$ for six months in adult insomniacs. ${ }^{25}$ Furthermore, no effects were found in a population of elderly patients when discontinuing after five weeks of treatment with ramelteon $4 \mathrm{mg}$ or $8 \mathrm{mg}$. Improvements relative to baseline were found on nights 1,2 , and 6 of the placebo runout week, as compared with placebo. ${ }^{30}$ Similarly, an absence of rebound insomnia was demonstrated by Zammit et al after administering ramelteon for five weeks in adults. ${ }^{26}$ On the first night after discontinuation of ramelteon, a significant greater reduction in latency to persistent sleep was found in the ramelteon $8 \mathrm{mg}$ group. There was no evidence of withdrawal effects.

\section{Adverse events}

According to the summary of product characteristics, based on 2861 patients with chronic insomnia, the most commonly observed adverse effects of ramelteon $8 \mathrm{mg}$ (versus placebo) 
were somnolence ( $3 \%$ versus $2 \%$ ), fatigue ( $3 \%$ versus $2 \%$ ), dizziness ( $4 \%$ versus $3 \%$ ), nausea ( $3 \%$ versus $2 \%$ ), and exacerbated insomnia ( $3 \%$ versus $2 \%){ }^{22}$

\section{Endocrine function}

Effects on endocrine function in adults with chronic insomnia (aged 18-45 years) were examined during treatment with ramelteon $16 \mathrm{mg}$ or placebo for six months. ${ }^{37}$ Patients had no significant endocrine pathology. No significant differences were found in thyroid function or adrenal function, or for most reproductive hormones. Women treated with ramelteon had higher prolactin levels, but this was not considered clinically relevant because no effects on the reproductive cycle were observed.

Endocrine function was also assessed in an open-label study in adult $(n=965$; ramelteon $16 \mathrm{mg})$ and elderly $(\mathrm{n}=248$; ramelteon $8 \mathrm{mg}$ ) insomnia patients. ${ }^{28}$ Ramelteon was administered for 48 weeks. Some changes in thyroid function were detected. With the exception of thyroxine, thyroid function returned to normal by the last visit, which was three days after withdrawal. Free testosterone was elevated in younger men in the initial months of the study, and was decreased throughout the study in older men. Morning cortisol levels were decreased at nearly all visits. In female participants, duration of menses was increased by one day on average.

\section{Safety in patients with breathing disorders}

Treating patients with sleep-related breathing disorders and comorbid insomnia can be challenging. Although clinical evidence is not straightforward, some benzodiazepines may have a potential for respiratory depression in certain patients. ${ }^{38-40}$ Therefore, it is of importance to assess the safety and efficacy of hypnotics in these patient populations. Ramelteon was examined in patients with sleep apnea and chronic obstructive pulmonary disease (COPD).

In double-blind, placebo-controlled studies of patients with mild to moderate $\mathrm{COPD}^{41}$ and moderate to severe COPD,${ }^{42}$ no effects of ramelteon $16 \mathrm{mg}$ and $8 \mathrm{mg}$ were found on arterial oxygen saturation $\left(\mathrm{SaO}_{2}\right)$ during sleep, or on the apnea-hypnopnea index (AHI, ie, the number of apneas and hypopneas per hour). Total sleep time and sleep efficiency increased in both studies. Similarly, in patients with mild to moderate obstructive sleep apnea, ${ }^{43}$ ramelteon $16 \mathrm{mg}$ had no effect on AHI or $\mathrm{SaO}_{2}$ compared with placebo, except for a significant increase in $\mathrm{SaO}_{2}$ compared with placebo during rapid eye movement sleep. No effects on objective or subjective sleep measures were found. Overall, ramelteon did not worsen sleep-disordered breathing, and is unlikely to exacerbate sleep apnea in patients with mild to moderate sleep apnea. However, the effects of prolonged intake have not been studied.

\section{Patients with hepatic or renal impairment}

In patients with mild hepatic impairment, exposure to ramelteon $16 \mathrm{mg}$ per day over a period of seven days was increased by almost four-fold. In patients with moderate hepatic impairment, exposure was increased by more than 10 -fold. No studies have been performed in patients with severe hepatic impairment. Therefore, ramelteon should be used with caution in patients with mild to moderate hepatic impairment, and is not recommended for patients with severe impairment. ${ }^{22}$ For patients with mild, moderate, or severe renal impairment or patients with chronic hemodialysis, no effects of ramelteon $16 \mathrm{mg}$ on systemic exposure to ramelteon or M-II were observed. As a result, no adjustment of dosage is required in these patients. ${ }^{22}$

\section{Abuse potential}

Concerns exist regarding the possible abuse of hypnotics. Clinical trials and animal studies have demonstrated no indications for abuse of ramelteon. ${ }^{4}$ In subjects with a history of drug use, Johnson et $\mathrm{al}^{44}$ examined the abuse potential for ramelteon, comparing the drug with placebo and triazolam. Drug strength and effect were examined using the Drug Effect Questionnaire and the Addiction Research Centre Inventory, respectively. In addition, monetary value was assessed with the Drug versus Money Choice procedure. Triazolam treatment led to significant differences compared with placebo in drug strength, abuse potential, and sedative drug effects. No indication of abuse potential was found for ramelteon. Griffiths and Johnson ${ }^{45}$ undertook a comparison of 19 of the most commonly used drugs in the treatment of insomnia. They compared relative abuse potential by assessing the interaction of the likelihood of abuse (ie, relative reinforcing effects) and toxicity (ie, probability that adverse effects harm the individual or society). Hypnotics that lacked affinity for the GABA receptor, ie, diphenhydramine, trazodone, and ramelteon, showed less likelihood of abuse. Ramelteon was the only drug in this group that scored very low on both measures.

\section{Drug interactions}

Drug-drug interactions are mainly expected with drugs that influence or are influenced by CYP1A2. Because CYP2C and CYP3A4 are involved in ramelteon metabolism, drugs 
that inhibit these isoenzymes should be used with caution. Fluvoxamine was found to raise serum ramelteon levels by 70 -fold, and should not be combined with ramelteon due to a risk of adverse effects. Rifampin, a strong CYP enzyme inducer, decreases ramelteon efficacy by lowering exposure to ramelteon and M-II. Ketoconazole increases the availability of ramelteon and M-II. The same was found for fluconazole. These drugs may increase the risk of adverse events when combined with ramelteon. ${ }^{4,22}$

\section{Behavioral effects Acute effects}

Three studies have examined the effects of ramelteon administered in the morning to assess possible dose-response effects. Pharmacodynamic effects were assessed in two studies. Age and gender effects of a single dose of ramelteon $16 \mathrm{mg}$ versus placebo were studied in 48 participants aged 18-79 years in a double-blind, crossover study, ${ }^{20}$ in which no effects on cognitive performance assessed by the digit symbol substitution test (DSST) or word recall were found. Self-rated sedation was significantly higher compared with placebo in young, elderly, male, and female subjects. Observer-rated sedation was increased in male and elderly subjects. Of importance is the lack of an association between serum AUC values for ramelteon, M-II, or both, and AUC values for self-rated sedation, observer-rated sedation, or the DSST. This suggests that the pharmacodynamic effects of ramelteon do not depend on systemic exposure to ramelteon and/or its metabolite. Similar results were obtained by Karim et al, ${ }^{21}$ who examined healthy adults aged $35-65$ years assigned to receive ramelteon $4,8,16,32$, or $64 \mathrm{mg}(\mathrm{n}=8$ per group) or placebo $(\mathrm{n}=20)$ in the morning. Again, no effect was found on the DSST, with small effects on alertness found in the $64 \mathrm{mg}$ group, but this was unrelated to peak plasma concentration.

Johnson et al examined ramelteon 16, 80, and $160 \mathrm{mg}$, placebo, and temazepam $0.25-0.75 \mathrm{mg}$ in 14 healthy adults aged 19-50 years with histories of recreational drug abuse. ${ }^{44}$ Ramelteon was administered in the morning, and measurements were performed 0.5 hours before intake and at hourly intervals for 1-12 hours after intake and 24 hours after intake, except for word learning (presented two hours and measured six hours after administration). Temazepam significantly impaired postural balance compared with placebo and ramelteon. Furthermore, in contrast with temazepam, ramelteon did not impair performance on the DSST, circular lights test, or word recall and recognition.

Furthermore, another study that assessed immediate and delayed memory recall in a word learning test in the middle of the night (two hours after dosing) found no effects of ramelteon, unlike zolpidem, which impaired immediate memory recall. ${ }^{46}$

\section{Postural stability}

Hypnotics have the potential to impair postural balance, which may, in turn, lead to falls and hip fractures. This is of special importance in the elderly. In addition, balance impairments are likely to occur around the time of peak plasma concentration. ${ }^{47}$ This does not seem to be the case for ramelteon. When the effect of ramelteon on balance, ie, the ability to stand upright on one foot with eyes closed, was assessed 1-12 hours after morning intake and after 24 hours, no effects were observed for doses up to $160 \mathrm{mg}$. In the same study, triazolam did show significant impairment. ${ }^{44}$ A study that utilized a more advanced technique to measure balance impairment confirmed this finding. In a single-dose crossover design, Zammit et $\mathrm{al}^{46}$ examined the influence of ramelteon $8 \mathrm{mg}$, zolpidem $10 \mathrm{mg}$, and placebo on a number of parameters of postural control in elderly adults with chronic insomnia ( $n=33$, age $\geq 65$ years). Two hours after bedtime, treated subjects were woken to test balance and mobility. Compared with placebo, zolpidem showed impairment in both the balance and mobility test, while no effect was found for ramelteon.

\section{Next-morning residual effects}

Hypnotics that act on the benzodiazepine receptor are known to produce residual next-morning sedation that may affect cognitive and psychomotor performance. Impairment of memory and psychomotor functioning and drowsiness can impair daily activities, such as driving a car. ${ }^{48}$ Studies assessing next-morning residual effects have measured DSST performance, memory, and subjective effects on mood using visual analog scales (VAS).

No study has found an effect of ramelteon on DSST performance. ${ }^{23,25-27,31}$ Furthermore, no effects were found on memory functioning assessed by immediate or delayed word recall, ${ }^{25,27,31}$ except for two studies. In the first, ramelteon was administered for five weeks. ${ }^{26}$ After weeks 1, 3, and 5, subjects had to remember a list of words and were tested on immediate recall in the evening. Delayed recall was tested the next morning. Relative to placebo, immediate word recall was decreased after three weeks of treatment ( 7.5 versus 8.2 words), and delayed word recall was impaired after one week of treatment (3.6 versus 4.2 words). No effects were found at other time points. The second study examined the phaseshifting properties of ramelteon, and showed impairments in 
immediate word recall after four nights of intake of ramelteon 1, 4, and $8 \mathrm{mg} \cdot{ }^{35}$

Reports of subjective mood, feelings, and alertness varied between studies. Alertness and ability to concentrate were not affected by ramelteon, ${ }^{25,27}$ or even improved, ${ }^{26}$ except for dosages of $64 \mathrm{mg}$, which led to small impairments after a single intake. ${ }^{23}$ One study found effects on individual items in VAS scores for drowsiness, being slowed down, and sleepiness after one week of intake of ramelteon $8 \mathrm{mg}$, and slowed thinking and fatigue after six months of treatment. ${ }^{25}$ An increase in the VAS for mood was also found after a single dose of ramelteon $16 \mathrm{mg}$ on the items of drowsiness, sleepiness, tiredness, and sluggishness. ${ }^{24}$

This was confirmed by another study in which effects on fatigue, irritability, and sluggishness were reported at several time points (week $1-3$ ). ${ }^{26}$ In contrast, no effects were found after two nights of ramelteon $4-32 \mathrm{mg},{ }^{27}$ whereas a study in the elderly showed improvements in irritability and calmness. ${ }^{31}$

\section{Discussion}

Ramelteon has a number of benefits over the benzodiazepine hypnotics and z-drugs. Ramelteon is well tolerated, has a low probability of abuse, and no next-day residual effects have been demonstrated. However, there are also a number of limitations. First, efficacy data obtained by polysomnography primarily show an effect on sleep onset latency. A moderate decrease in latency to persistent sleep was demonstrated, both in models of transient insomnia in healthy volunteers and in chronic insomnia patients. When compared with placebo, this reduction varied from 7 to 19 minutes and averaged around 13 minutes. This effect was found to last up to six months after initiation of treatment, and is comparable with that of other hypnotics. Findings from a meta-analysis ${ }^{49}$ showed an average of 10 minutes $(95 \% \mathrm{CI}$ : $-16.6,-3.4)$ reduction in sleep onset latency for benzodiazepine hypnotics, and 12.8 minutes for nonbenzodiazepines (95\% CI: $-16.9,-8.8)$. Other polysomnographic measures showed limited effects, with increases in total sleep time found in all studies, but the effect was relatively small, ie, 9-22 minutes, and lasted for up to only one week after treatment onset. Second, patient reports on sleep measures showed some inconsistency, in that subjective sleep latency and total sleep time were improved in some but not all studies, whereas sleep quality was not affected in any of the studies. Because insomnia is defined as a subjective report of sleep disturbance, ${ }^{50}$ a hypnotic should ideally improve subjective sleep measures. Subjective sleep latency was only decreased in some studies and was sustained when treatment was given for five weeks, whereas subjective reports on total sleep time varied. Other subjective effects were lacking or inconsistent. A few studies have demonstrated significant decreases in subjective sleep latency, ranging from 11.4 to 18.5 minutes in adults, and from 7.2 to 12.9 minutes in elderly subjects. According to the aforementioned metaanalysis, averages for benzodiazepine hypnotics are $19.6 \mathrm{~min}$ utes (95\% CI: $-23.9,-15.3)$ and 17.0 minutes (95\% CI: $-22.3,-2.2)$ for nonbenzodiazepine hypnotics. ${ }^{49}$ Although an active control has been used in a number of clinical studies, no direct comparisons have been made between the efficacy of ramelteon and benzodiazepine receptor agonists.

Likewise, the effects of ramelteon have not been compared with those of melatonin or its agonists. The efficacy of melatonin is inconclusive, and a recent meta-analysis failed to show a significant effect on sleep onset latency. ${ }^{51}$ However, another meta-analysis ${ }^{52}$ showed that melatonin, in varying dosages, led to an average decrease in objective sleep onset latency of four minutes, as well as to increases in sleep efficiency and total sleep duration. However, the clinical relevance of this decrease is unclear.

Safety data show that, overall, ramelteon is well tolerated and has little or no effect on next-day performance. Memory and psychomotor tests show no noteworthy impairment, whereas there have been only a few reports on mood. However, most studies only applied two methods to test memory and psychomotor functioning, ie, the world learning test and the DSST. One study also used the circular lights test and showed no effect. More complex behavioral skills may show impairments and should therefore be studied. Balance was not influenced by ramelteon, which suggests it is a safe alternative, especially for elderly patients. Although balance impairment on the morning after intake is unlikely, this has not been assessed thus far. Studies show that ramelteon is safe in patients with sleep-related breathing difficulties and in those with renal failure, but this agent should be used with caution in patients with mild to moderate hepatic impairment. No major endocrine effects have been observed, but the findings of one open-label study suggest that further studies related to hormonal functioning in females and on age-related effects are necessary. In addition, there is some evidence that the use of melatonergic agonists may be problematic in patients with autoimmune diseases, parkinsonism, and irritable bowel syndrome Type II. ${ }^{53}$ An important benefit of ramelteon over other types of hypnotics is that it is the only hypnotic drug that has been found to have virtually no abuse potential. In addition, no rebound insomnia has been observed. 
In line with its indication for use, ramelteon may be preferred in patients with sleep onset difficulties. However, this is unlikely for sleep maintenance problems. In addition, some evidence for application in patients with anxiety warrants further investigation in this and other types of mental disorders with comorbid insomnia. Furthermore, preliminary evidence suggests that ramelteon may be effective in the treatment of circadian rhythm disorders. Future studies in patient populations, such as individuals with shift work sleep disorder or delayed sleep phase disorder, should provide more insight into its use for these indications and provide information on long-term safety and efficacy. Overall, in patients with insomnia and in patients with circadian rhythm disturbances, long-term treatment may occur and should therefore be carefully evaluated. Moreover, to clarify the chronobiotic actions of ramelteon, a phase-response curve for ramelteon should be determined, as has been established for melatonin. ${ }^{54}$

In conclusion, currently available knowledge on ramelteon shows that it is both safe and well tolerated. Its usefulness seems primarily limited to patients with sleep onset difficulties. The applicability of ramelteon in other disorders has yet to be established.

\section{Disclosure}

JC Verster is a consultant/advisor to Sepracor and Red Bull $\mathrm{GmbH}$ and has received research support from Wyeth Ayerst Research, Takeda Pharmaceuticals, UCB Pharma, and Red Bull GmbH.

\section{References}

1. Ebert B, Wafford KA, Deacon S. Treating insomnia: Current and investigational pharmacological approaches. Pharmacol Ther. 2006;112(3):612-629.

2. Terzano MG, Rossi M, Palomba V, Smerieri A, Parrino L. New drugs for insomnia: Comparative tolerability of zopiclone, zolpidem and zaleplon. Drug Saf. 2003;26(4):261-282.

3. Wilson S, Nutt D. Management of insomnia: Treatments and mechanisms. Br J Psychiatry. 2007;191(3):195-197.

4. FDA labelling information. Available from: http://www.accessdata.fda. gov/drugsatfda_docs/label/2008/021782s008s009s010lbl.pdf. Accessed 2010 Sep 30.

5. European Medicines Agency. Withdrawal assessment report for Ramelteon. 2008. Available from: http://www.emea.europa.eu/docs/ en_GB/document_library/Application_withdrawal_assessment_ report/2010/01/WC500064663.pdf. Accessed 2010 Sep 30.

6. Pandi-Perumal SR, Srinivasan V, Spence DW, et al. Ramelteon: A review of its therapeutic potential in sleep disorders. Adv Ther. 2009;26(6):613-626.

7. Reynoldson JN, Elliott ES, Nelson LA. Ramelteon: A novel approach in the treatment of insomnia. Ann Pharmacother. 2008;42(9): 1262-1271.

8. Simpson D, Curran MP. Ramelteon: A review of its use in insomnia. Drugs. 2008;68(13):1901-1909.

9. Dubocovich ML. Melatonin receptors: Role on sleep and circadian rhythm regulation. Sleep Med. 2007;8 Suppl 3:34-42.
10. Pandi-Perumal SR, Srinivasan V, Spence DW, Cardinali DP. Role of the melatonin system in the control of sleep: Therapeutic implications. CNS Drugs. 2007;21(12):995-1018.

11. Jockers R, Maurice P, Boutin JA, Delagrange P. Melatonin receptors, heterodimerization, signal transduction and binding sites: What's new? Br J Pharmacol. 2008;154(6):1182-1195.

12. Jan JE, Reiter RJ, Wasdell MB, Bax M. The role of the thalamus in sleep, pineal melatonin production, and circadian rhythm sleep disorders. J Pineal Res. 2009;46(1):1-7.

13. Dijk DJ, Shanahan TL, Duffy JF, Ronda JM, Czeisler CA. Variation of electroencephalographic activity during non-rapid eye movement and rapid eye movement sleep with phase of circadian melatonin rhythm in humans. J Physiol. 1997;505(Pt 3):851-858.

14. Dijk DJ, Roth C, Landolt HP, et al. Melatonin effect on daytime sleep in men: Suppression of EEG low frequency activity and enhancement of spindle frequency activity. Neurosci Lett. 1995;201(1):13-16.

15. Kato K, Hirai K, Nishiyama K, et al. Neurochemical properties of ramelteon (TAK-375), a selective MT1/MT2 receptor agonist. Neuropharmacology. 2005;48(2):301-310.

16. France CP, Weltman RH, Koek W, Cruz CM, McMahon LR. Acute and chronic effects of ramelteon in rhesus monkeys (Macaca mulatta): Dependence liability studies. Behav Neurosci. 2006;120(3):535-541.

17. Hirai K, Kita M, Ohta H, et al. Ramelteon (TAK-375) accelerates reentrainment of circadian rhythm after a phase advance of the light-dark cycle in rats. J Biol Rhythms. 2005;20(1):27-37.

18. Miyamoto M. Effect of ramelteon (TAK-375), a selective MT1/MT2 receptor agonist, on motor performance in mice. Neurosci Lett. 2006; 402(3):201-204

19. Nishiyama K, Shintani Y, Hirai K, Yoshikubo S. Molecular cloning and pharmacological characterization of monkey MT1 and MT2 melatonin receptors showing high affinity for the agonist ramelteon. J Pharmacol Exp Ther. 2009;330(3):855-863.

20. Greenblatt DJ, Harmatz JS, Karim A. Age and gender effects on the pharmacokinetics and pharmacodynamics of ramelteon, a hypnotic agent acting via melatonin receptors MT1 and MT2. J Clin Pharmacol. 2007;47(4):485-496.

21. Karim A, Tolbert D, Cao C. Disposition kinetics and tolerance of escalating single doses of ramelteon, a high-affinity MT1 and MT2 melatonin receptor agonist indicated for treatment of insomnia. J Clin Pharmacol. 2006;46(2):140-148.

22. Rozerem ${ }^{\circledR}$ prescribing information. Takeda, 2008. Available from: http://hcp.rozerem.com/. Accessed 2010 Sep 30.

23. Roth T, Stubbs C, Walsh JK. Ramelteon (TAK-375), a selective MT1/MT2-receptor agonist, reduces latency to persistent sleep in a model of transient insomnia related to a novel sleep environment. Sleep. 2005;28(3):303-307.

24. Zammit G, Schwartz H, Roth T, Wang-Weigand S, Sainati S, Zhang J. The effects of ramelteon in a first-night model of transient insomnia. Sleep Med. 2009;10(1):55-59.

25. Mayer G, Wang-Weigand S, Roth-Schechter B, Lehmann R, Staner C, Partinen M. Efficacy and safety of 6-month nightly ramelteon administration in adults with chronic primary insomnia. Sleep. 2009;32(3):351-360.

26. Zammit G, Erman M, Wang-Weigand S, Sainati S, Zhang J, Roth T. Evaluation of the efficacy and safety of ramelteon in subjects with chronic insomnia. J Clin Sleep Med. 2007;3(5):495-504.

27. Erman M, Seiden D, Zammit G, Sainati S, Zhang J. An efficacy, safety, and dose-response study of Ramelteon in patients with chronic primary insomnia. Sleep Med. 2006;7(1):17-24.

28. Richardson GS, Zammit G, Wang-Weigand S, Zhang J. Safety and subjective sleep effects of ramelteon administration in adults and older adults with chronic primary insomnia: A 1-year, open-label study. J Clin Psychiatry. 2009;70(4):467-476.

29. Wang-Weigand S, McCue M, Ogrinc F, Mini L. Effects of ramelteon $8 \mathrm{mg}$ on objective sleep latency in adults with chronic insomnia on nights 1 and 2: Pooled analysis. Curr Med Res Opin. 2009;25(5):1209-1213. 
30. Roth T, Seiden D, Sainati S, Wang-Weigand S, Zhang J, Zee P. Effects of ramelteon on patient-reported sleep latency in older adults with chronic insomnia. Sleep Med. 2006;7(4):312-318.

31. Roth T, Seiden D, Wang-Weigand S, Zhang J. A 2-night, 3-period, crossover study of ramelteon's efficacy and safety in older adults with chronic insomnia. Curr Med Res Opin. 2007;23(5):1005-1014.

32. Mini LJ, Wang-Weigand S, Zhang J. Self-reported efficacy and tolerability of ramelteon $8 \mathrm{mg}$ in older adults experiencing severe sleep-onset difficulty. Am J Geriatr Pharmacother. 2007;5(3):177-184.

33. Gross PK, Nourse R, Wasser TE. Ramelteon for insomnia symptoms in a community sample of adults with generalized anxiety disorder: An open label study. J Clin Sleep Med. 2009;5(1):28-33.

34. Richardson GS, Zee PC, Wang-Weigand S, Rodriguez L, Peng X. Circadian phase-shifting effects of repeated ramelteon administration in healthy adults. J Clin Sleep Med. 2008;4(5):456-461.

35. Zee PC, Wang-Weigand S, Wright KP, Peng X, Roth T. Effects of ramelteon on insomnia symptoms induced by rapid, eastward travel. Sleep Med. 2010;11(6):525-533.

36. Tyrer P, Murphy S, Riley P. The benzodiazepine withdrawal symptom questionnaire. J Affect Disord. 1990;19(1):53-61.

37. Richardson G, Wang-Weigand S. Effects of long-term exposure to ramelteon, a melatonin receptor agonist, on endocrine function in adults with chronic insomnia. Hum Psychopharmacol. 2009;24(2):103-111.

38. Roth T. Hypnotic use for insomnia management in chronic obstructive pulmonary disease. Sleep Med. 2009;10(1):19-25.

39. Lavie P. Insomnia and sleep-disordered breathing. Sleep Med. 2007; 8 Supp1 4:S21-S25.

40. Stege G, Vos PJ, van den Elshout FJ, Richard Dekhuijzen PN, van de Ven MJ, Heijdra YF. Sleep, hypnotics and chronic obstructive pulmonary disease. Respir Med. 2008;102(6):801-814.

41. Kryger M, Wang-Weigand S, Zhang J, Roth T. Effect of ramelteon, a selective MT(1)/MT (2)-receptor agonist, on respiration during sleep in mild to moderate COPD. Sleep Breath. 2008;12(3):243-250.

42. Kryger M, Roth T, Wang-Weigand S, Zhang J. The effects of ramelteon on respiration during sleep in subjects with moderate to severe chronic obstructive pulmonary disease. Sleep Breath. 2009;13(1):79-84.
43. Kryger M, Wang-Weigand S, Roth T. Safety of ramelteon in individuals with mild to moderate obstructive sleep apnea. Sleep Breath. 2007;11(3):159-164.

44. Johnson MW, Suess PE, Griffiths RR. Ramelteon: A novel hypnotic lacking abuse liability and sedative adverse effects. Arch Gen Psychiatry. 2006;63(10):1149-1157.

45. Griffiths RR, Johnson MW. Relative abuse liability of hypnotic drugs: A conceptual framework and algorithm for differentiating among compounds. J Clin Psychiatry. 2005;66 Suppl 9:31-41.

46. Zammit G, Wang-Weigand S, Rosenthal M, Peng X. Effect of ramelteon on middle-of-the-night balance in older adults with chronic insomnia. J Clin Sleep Med. 2009;5(1):34-40.

47. Mets MAJ, Volkerts ER, Olivier B, Verster JC. Effect of hypnotic drugs on body balance and standing steadiness. Sleep Med Rev. 2010;14(4):259-267.

48. Verster JC, Veldhuijzen DS, Volkerts ER. Residual effects of sleep medication on driving ability. Sleep Med Rev. 2004;8(4): 309-325.

49. Buscemi N, Vandermeer B, Friesen C, et al. The efficacy and safety of drug treatments of chronic insomnia in adults: A meta-analysis of RCTs. J Gen Intern Med. 2007;22(9):1335-1350.

50. American Academy of Sleep Medicine. International Classification of Sleep Disorders. Diagnostic and Coding Manual. 2nd ed. Westchester IL: American Academy of Sleep Medicine; 2005.

51. Buscemi N, Vandermeer B, Hooton N, et al. Efficacy and safety of exogenous melatonin for secondary sleep disorders and sleep disorders accompanying sleep restriction: Meta-analysis. $B M J$. 2006;332(7538):385-393

52. Brzezinski A, Vangel MG, Wurtman RJ, et al. Effects of exogenous melatonin on sleep: A meta-analysis. Sleep Med Rev. 2005;9(1):41-50.

53. Hardeland R. New approaches in the management of insomnia: Weighing the advantages of prolonged-release melatonin and synthetic melatoninergic agonists. Neuropsychiatr Dis Treat. 2009;5:341-354.

54. Lewy AJ, Ahmed S, Jackson JM, Sack RL. Melatonin shifts human circadian rhythms according to a phase-response curve. Chronobiol Int. 1992;9(5):380-392.
Nature and Science of Sleep

\section{Publish your work in this journal}

Nature and Science of Sleep is an international, peer-reviewed, open access journal covering all aspects of sleep science and sleep medicine, including the neurophysiology and functions of sleep, the genetics of sleep, sleep and society, biological rhythms, dreaming, sleep disorders and therapy, and strategies to optimize healthy sleep. The journal welcomes

\section{Dovepress}

original research, clinical \& epidemiological studies, reviews \& evaluations, case reports and extended reports. The manuscript management system is completely online and includes a very quick and fair peerreview system, which is all easy to use. Visit http://www.dovepress.com/ testimonials.php to read real quotes from published authors. 